ARTICLE

https://doi.org/10.1038/s41467-019-11524-y

\title{
Fast and selective organocatalytic ring-opening polymerization by fluorinated alcohol without a cocatalyst
}

Wei Zhao ${ }^{1}{ }^{1}$, Yanfeng $\mathrm{Lv}^{1}$, Ji Li ${ }^{1}$, Zihao Feng ${ }^{1}$, Yonghao $\mathrm{Ni}^{2} \&$ Nikos Hadjichristidis ${ }^{3}$

Organocatalysis is an important branch of catalysis for various organic transformations and materials preparation. Polymerizations promoted by organic catalysts can produce polymeric materials without any metallic residues, providing charming materials for high-value and sensitive domains such as biomedical applications, microelectronic devices and food packaging. Herein, we describe a fluorinated alcohol based catalytic system for polypeptide synthesis via catalytic ring-opening polymerization (ROP) of $\alpha$-amino acid $\mathrm{N}$-carboxyanhydride (NCA), fulfilling cocatalyst free, metal free, high rate and high selectivity. During polymerization, the fluorinated alcohol catalyst forms multiple dynamic hydrogen bonds with the initiator, monomer and propagating polymer chain. These cooperative hydrogen bonding interactions activate the NCA monomers and simultaneously protect the overactive initiator/ propagating polymer chain-ends, which offers the whole polymerization with high activity and selectivity. Mechanistic studies indicate a monocomponent-multifunctional catalytic mode of fluorinated alcohol. This finding provides a metal free and fast approach to access well-defined polypeptides.

\footnotetext{
${ }^{1}$ College of Bioresources Chemical and Materials Engineering, Shaanxi University of Science and Technology, 710021 Xi'an, People's Republic of China. ${ }^{2}$ Department of Chemical Engineering, University of New Brunswick, Fredericton, New Brunswick E3B 5A3, Canada. ${ }^{3}$ KAUST Catalysis Center, Polymer Synthesis Laboratory, Physical Sciences and Engineering Division, King Abdullah University of Science and Technology (KAUST), Thuwal 23955, Saudi Arabia. Correspondence and requests for materials should be addressed to W.Z. (email: zhwgah1028@126.com)
} 
S ynthetic polypeptides, as mimics of natural analogues, is a unique family of bio-inspired biomaterials with broad biomedical applications including controlled drug release, gene delivery, tissue engineering, and regenerative medicine ${ }^{1,2}$. Ringopening polymerization (ROP) of $\alpha$-amino acid $\mathrm{N}$ carboxyanhydrides (NCAs) initiated by different amines and amines derivatives is considered to be the most common method for polypeptide synthesis. However, in the ROP of NCAs, the normal amine mechanism (NAM) and activated monomer mechanism (AMM), often compete with each other, which complicates the overall polymerization process, making it challenging to produce well-defined (co)polypeptides (see Supplementary fig. 1$)^{3,4}$. In 1997, Deming reported the first example of controlled/living ROP of NCAs by using transition metal complexes instead of traditional primary amine as active species to control the monomer addition at polymer chain-end ${ }^{5,6}$. Since then, a few studies on controlled NCA polymerizations have been reported, by designing new initiators (e.g., Pt complexes ${ }^{7}$, ammonium salts $^{8}$, silazane derivatives ${ }^{9}$, rare earth metal complexes $^{10}$, amine-borane Lewis pairs ${ }^{11}$, and Li complex ${ }^{12}$ ) or by exploring new reaction conditions for the traditional primary amine-initiated polymerizations (e.g., high vacuum ${ }^{13,14}$, low temperature ${ }^{15-17}$, and nitrogen flowing ${ }^{18}$ ). As for the ROP of NCA promoted by metal complexes, the metal residues in resultant polypeptides can cause toxicity concerns. An extra purification of the as-synthesized polymer such as dialysis is usually required. In regards to the NCA polymerizations initiated by organic initiators, low polymerization activities are usually observed, even with low monomer/initiator ratios $8,9,11$, showing limitations in the synthesis of polypeptides with high molecular weights and/or for ROP of NCAs with low stabilities. Therefore, developing a fast and metal-free process for the synthesis of polypeptides is very necessary and promising.

Hydrogen-bonding is widely effective in biological systems, playing a crucial role in sustaining the elegant architecture/ functionality of proteins and nucleic acids ${ }^{19-21}$. In an analogous manner to natural systems, organocatalysis utilizing hydrogen bonding to accelerate and control chemical reactions is of particular interest in organic chemistry and has become an active and vibrant research area in the past two decades ${ }^{22-25}$. Numerous classes of compounds such as binols ${ }^{26-28}$, silane diols ${ }^{29,30}$, squaramides $^{31,32}$, (thio)ureas ${ }^{33,34}$, guanidine ${ }^{35}$, and amidine functionalities ${ }^{36}$ have been explored for various organic transformations. Furthermore, as an elegant alternative to organometallic and enzymatic catalysis, hydrogen-bonding organocatalysis has been a promising pathway for innovative polymer synthesis, especially for the preparation of metal-free polymers required for advanced packaging, medical and microelectronic applications ${ }^{37-42}$.

In recent years, fluorinated alcohols have attracted extensive research interest due to their special properties such as lower boiling points and higher melting points than their nonfluorinated counterparts, high polarity, and strong hydrogenbonding capacity. Because of these specificities, fluorinated alcohols, as solvents, cosolvents, and additives, have noteworthy applications $\mathrm{s}^{43,44}$. For example, in biochemistry trifluoroethyl alcohol (TFE) and hexafluoroisopropyl alcohol (HFIP) are used to modify the conformation of proteins ${ }^{45-47}$. In organic chemistry, fluorinated alcohols are widely accepted as exceptional promotion media to perform organic reactions ${ }^{43,48-50}$, including oxidation reactions with $\mathrm{H}_{2} \mathrm{O}_{2}$ or sodium hypochlorite $e^{51-53}$, azaMichael reaction ${ }^{54}$, protection and deprotection of amine groups $^{55,56}$, cyclopropanation of alkenes ${ }^{57}$, and oxirane ringopening 58,59 . In polymer chemistry, fluorinated alcohols are effective solvents to control the stereospecificity of atom transfer radical polymerization (ATRP) $)^{60-63}$ and conventional radical polymerization ${ }^{64,65}$. So far, fluorinated alcohols, as small molecule metal free catalysts, rather than reaction mediums for polymer synthesis, are seldom explored. The only attempt refers to a fluorinated alchohol/(-)-sparteine bicomponent catalytic system developed by Hedrick et al. for ROP of cyclic esters, in which a fluorinated alcohol is used to activate the monomer and an organic base cocatalyst (-)-sparteine to activate the initiating/ propagating alcohol. Without $(-)$-sparteine, the polymerization cannot happen (Fig. 1a) ${ }^{66}$ To the best of our knowledge, so far there has been no report of utilizing a fluorinated alcohol as a catalyst for polymerization in the absence of base cocatalyst.

In this contribution, we show that 1,3-bis(2-hydroxyhexafluoroisopropyl)benzene (1,3-Bis-HFAB), a small fluorinated alcohol, without the assistance of a Lewis base cocatalyst, can catalyze a fast and selective ROP of $\alpha$-amino acid $N$-carboxyanhydride (NCA), resulting in well-defined polypeptides. Different from the bicomponent-bifunctional catalytic process of fluorinated alchohol/(-)-sparteine system for ROP of cyclic esters $^{66}$, the 1,3-Bis-HFAB catalyst doesn't require a Lewis base cocatalyst, and it is defined as a monocomponent-multifunctional catalytic process for ROP of NCA (Fig. 1b). During polymerization, 1,3-Bis-HFAB can form multiple dynamic hydrogen bondings with initiator, monomer and propagating polymer chainend, moving between them. These cooperative hydrogen-bonding interactions activate the monomer and simultaneously protect the overactive initiator/polymer chain from side reactions, offering high reaction rates and selectivity in the polymerization (Fig. 2). This finding not only represents a nonconventional catalysis

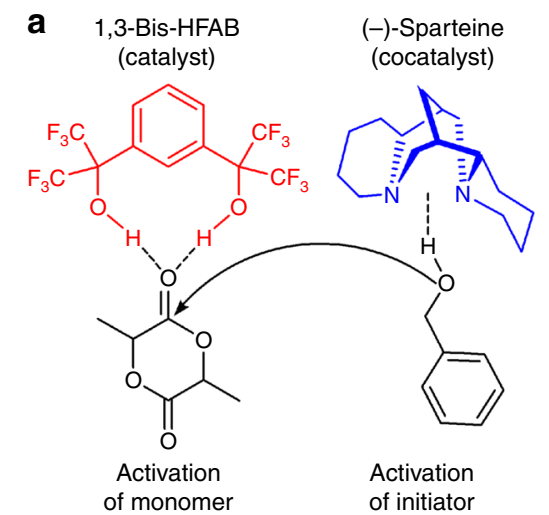

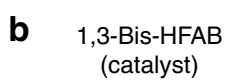

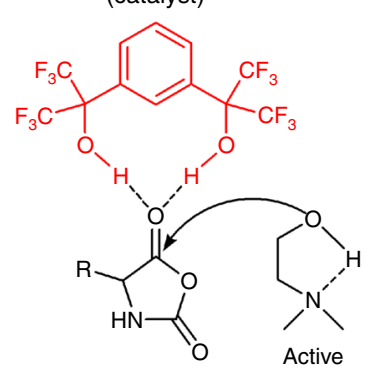

Activation

of monomer

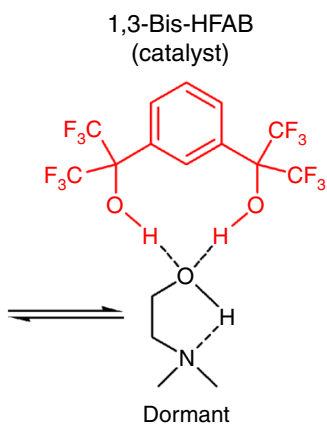

Dynamic protection of initiator

Fig. 1 Two different fluorinated alcohol based organocatalytic systems for ROP. a the bicomponent-bifunctional fluorinated alcohol/(-)-sparteine catalytic system for ROP of cyclic esters in which cocatalyst base, (-)-sparteine, is required. $\mathbf{b}$ the concept of monocomponent-multifunctional fluorinated alcohol catalytic system to be developed for ROP of NCA in this study 

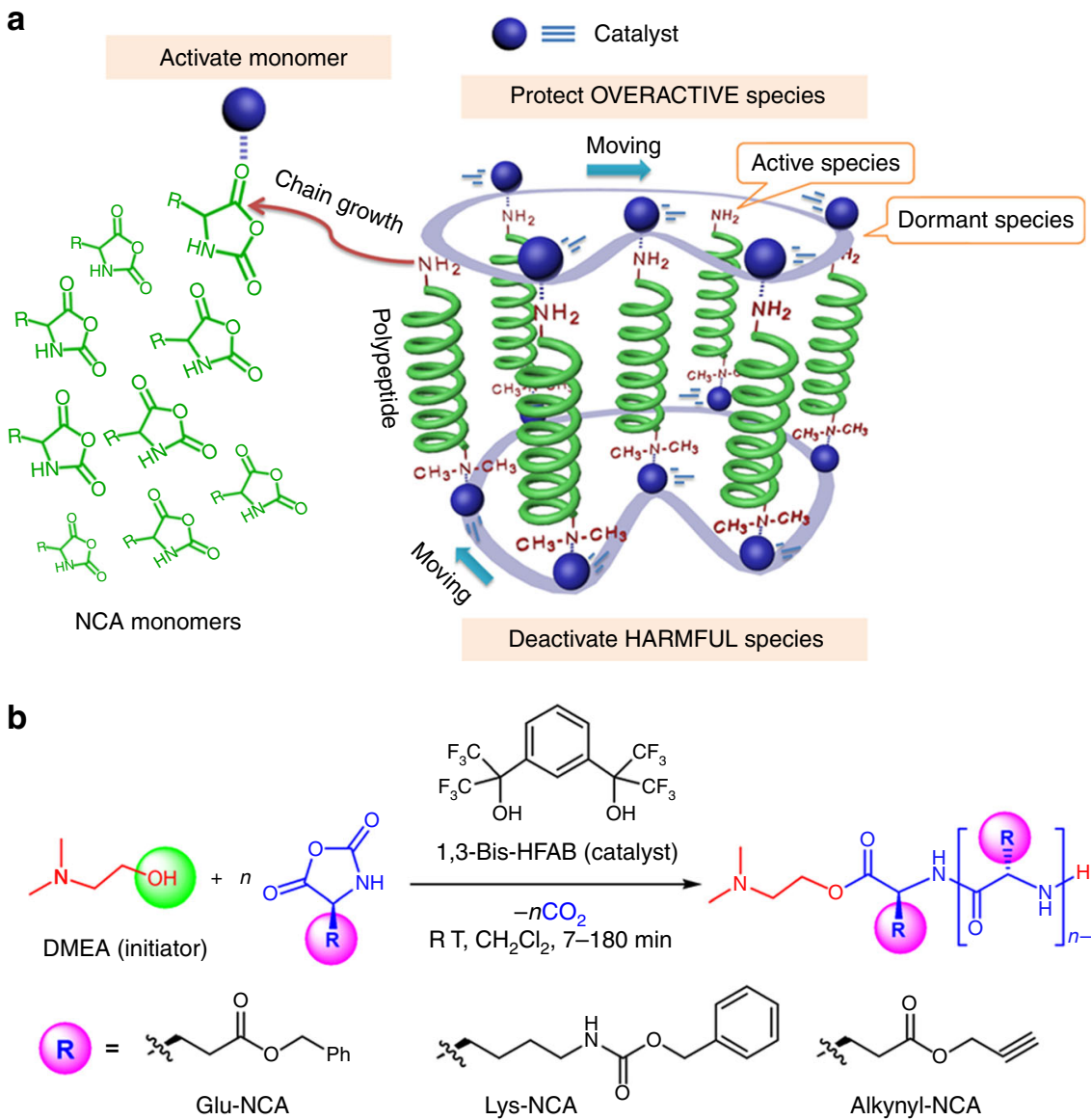

Fig. 2 Organocatalytic ROP of $\alpha$-amino acid N-carboxyanhydride (NCA) by fluorinated alcohol. a schematic diagram of the roles of fluorinated alcohol catalyst played during polymerization; b (co)polymerization of Glu-NCA, Lys-NCA, and Alkynyl-NCA initiated by DMEA in the presence of fluorinated alcohol catalyst 1,3-Bis-HFAB

methodology of fluorinated alcohols but also provides a pathway for polypeptides synthesis, fulfilling metal free, high activity, and high selectivity. Other merits of this strategy are: (1) the 1,3-BisHFAB catalyst and the aminoalcohol initiator used in this study are all commercially available organic chemicals, (2) the catalyst can be easily removed from final polypeptide after polymerization, which provides a facile way to get clean polypeptides for researchers who focus on the functions and applications of polypeptides but have backgrounds other than organic chemistry.

\section{Results}

Ring-opening polymerization of Glu-NCA promoted by 1,3Bis-HFAB. The catalytic performance of 1,3-Bis-HFAB for ROP of Glu-NCA was evaluated by using a small aminoalcohol molecule, $N, N$-dimethylethanolamine (DMEA), as the initiator. The catalyst 1,3-Bis-HFAB and the initiator DMEA were dissolved in dichloromethane, followed by introduction of a dichloromethane solution of Glu-NCA monomer at room temperature. Under these conditions, the polymerization reaction proceeded not only at a high rate but also high selectivity, with negligible side reactions, such as chain-transfer and chaintermination. As shown in Table 1, for a monomer-to-initiator ratio of $120([\mathrm{Glu}-\mathrm{NCA}] /[\mathrm{DMEA}]=120)$ and 1 equiv. 1,3-BisHFAB in dichloromethane, the NCA monomer was completely converted to polypeptide in just $7 \mathrm{~min}$ at room temperature, producing polypeptide with a narrow molecular weight distribution $Đ\left(Đ=\mathrm{M}_{\mathrm{w}} / \mathrm{M}_{\mathrm{n}}=1.07, \mathrm{M}_{\mathrm{n}, \mathrm{SEC}}=4.5 \times 10^{4}\right.$; Table 1, run 1). When the monomer-to-initiator ratio ([Glu-NCA]/[DMEA]) was gradually increased from 120 to 1920 by decreasing the concentration of initiator [DMEA] ([Glu-NCA] and [1,3-BisHFAB] were fixed, Table 1, runs 1-5), the molecular weights $\left(\mathrm{M}_{\mathrm{n}, \mathrm{SEC}}\right)$ of polypeptides increased linearly as a function of [Glu$\mathrm{NCA}] /[\mathrm{DMEA}]$ ratio and the molecular weight distributions remained narrow $(Đ=1.05-1.07)$, indicative of the living nature of the polymerization (Fig. 3a, b). The end-group analysis of a low molecular weight sample, prepared under analogous conditions, by ${ }^{1} \mathrm{H}$ NMR spectroscopy gave further support of the living nature of the polymerization. The resonances of DMEA were evident in the ${ }^{1} \mathrm{H}$ NMR spectrum and the $M_{n, N M R}$ calculated based on ${ }^{1} \mathrm{H}$ NMR spectrum was close to the theoretical value (Fig. 3c). The chemical structure of the obtained polypeptide was supported further by matrix-assisted laser desorption/ionization time-of-flight mass spectroscopy (MALDI-TOF MS). In the MALDI-TOF mass spectrum of oligomeric polypeptide, only one population was found (Fig. 3d). Based on the $\mathrm{m} / \mathrm{z}$ value, a formula of $\left\{\left(\mathrm{CH}_{3}\right)_{2} \mathrm{NCH}_{2} \mathrm{CH}_{2} \mathrm{O}-\left[\mathrm{COCH}\left(\mathrm{CH}_{2} \mathrm{CH}_{2} \mathrm{COOCH}_{2} \mathrm{C}_{6} \mathrm{H}_{5}\right) \mathrm{NH}\right]_{n^{-}}\right.$ $\left.\mathrm{COCF}_{3}\right\} \mathrm{H}^{+}(n=7-23)$ was established, which is in good agreement with an oligomeric polypeptide having $-\mathrm{NH}_{2}$ and DMEA end-groups $\left(\mathrm{M}_{\mathrm{MS}}=3450, \mathrm{Ð}_{\mathrm{MS}}=1.05\right)$. These results suggest that with DMEA as an initiator, the NCA monomers can undergo rapid and selective polymerization, giving polypeptides with welldefined molecular weight and low $Đ$.

Besides possessing a high selectivity for propagating chains, the ROP of Glu-NCA promoted by 1,3-Bis-HFAB exhibits high activities. When the [Glu-NCA]/[DMEA] ratio was changed from 120 to 960 by varying the initiator concentration [DMEA] (Table 1, runs 1-4), all polymerizations could be completed in $70 \mathrm{~min}$. Even at a high [Glu-NCA]/[DMEA] ratio up to 1920 , the 
Table 1 Living polymerization of NCAs promoted by 1,3-Bis-HFAB

\begin{tabular}{|c|c|c|c|c|c|c|c|}
\hline Runa & Monomer & [M]/[I]/[Cat.] & [Cat.] (mol\%) & time (min) & $M_{n, \text { calcd }} \times 10^{-4 b}$ & $M_{n, S E C} \times 10^{-4 c}$ & $\bigoplus^{c}$ \\
\hline 1 & Glu-NCA & $120 / 1 / 1$ & 0.8 & 7 & 2.63 & 4.57 & 1.07 \\
\hline 2 & Glu-NCA & $120 / 0.5 / 1$ & 0.8 & 13 & 5.26 & 7.43 & 1.08 \\
\hline 3 & Glu-NCA & $120 / 0.25 / 1$ & 0.8 & 25 & 10.52 & 12.72 & 1.04 \\
\hline 4 & Glu-NCA & $120 / 0.125 / 1$ & 0.8 & 70 & 21.04 & 20.33 & 1.04 \\
\hline 5 & Glu-NCA & $120 / 0.0625 / 1$ & 0.8 & 180 & 37.88 & 35.87 & 1.05 \\
\hline 6 & Glu-NCA & $120 / 1 / 2$ & 1.6 & 8.5 & 2.63 & 4.16 & 1.06 \\
\hline 7 & Glu-NCA & $120 / 1 / 4$ & 3.2 & 10.5 & 2.63 & 3.68 & 1.07 \\
\hline 8 & Glu-NCA & $120 / 1 / 6$ & 4.8 & 12.5 & 2.63 & 3.49 & 1.05 \\
\hline 9 & Glu-NCA & $120 / 1 / 8$ & 6.4 & 15 & 2.63 & 3.43 & 1.04 \\
\hline 10 & Glu-NCA & $120 / 1 / 10$ & 8 & 16 & 2.63 & 3.15 & 1.04 \\
\hline 11 & Lys-NCA & $120 / 1 / 1$ & 0.8 & 9 & 3.15 & 3.35 & 1.06 \\
\hline 12 & Lys-NCA & $120 / 0.5 / 1$ & 0.8 & 16 & 6.30 & 6.65 & 1.08 \\
\hline 13 & Lys-NCA & $120 / 0.25 / 1$ & 0.8 & 35 & 12.59 & 13.01 & 1.07 \\
\hline 14 & Alkynyl-NCA & $120 / 1 / 1$ & 0.8 & 8 & 2.01 & 2.31 & 1.05 \\
\hline 15 & Alkynyl-NCA & $120 / 0.5 / 1$ & 0.8 & 15 & 4.01 & 4.21 & 1.07 \\
\hline $16^{d}$ & Glu/Lys-NCA & $(60+60) / 1 / 1$ & 0.8 & $5+5$ & 2.89 & 3.08 & 1.08 \\
\hline $17^{e}$ & Glu/Lys-NCA & $(60+60) / 1 / 1$ & 0.8 & 10 & 2.89 & 3.16 & 1.05 \\
\hline $18^{f}$ & Glu/Alkynyl-NCA & $(60+60) / 1 / 1$ & 0.8 & $5+5$ & 2.32 & 2.48 & 1.07 \\
\hline 198 & Glu/Alkynyl-NCA & $(60+60) / 1 / 1$ & 0.8 & $5+5$ & 2.32 & 2.61 & 1.04 \\
\hline \multicolumn{8}{|c|}{ 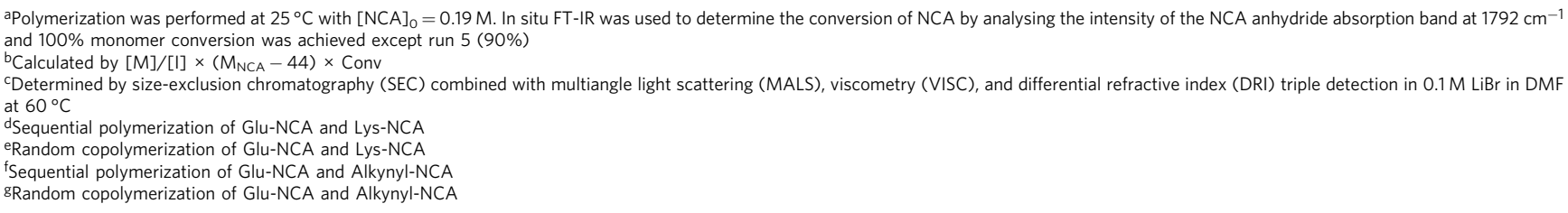 } \\
\hline
\end{tabular}

polymerization proceeded at a considerably high rate, and initiator loading could be as low as $0.01 \mathrm{~mol} \%$ (vs. [Glu-NCA]) without significant loss of activity. Ninety percent monomer conversion was achieved in $3 \mathrm{~h}$, producing a polypeptide with narrow molecular weight distribution and a molecular weight close to the theoretical value $\left(Đ=\mathrm{M}_{\mathrm{w}} / \mathrm{M}_{\mathrm{n}}=1.05, \mathrm{M}_{\mathrm{n}, \mathrm{SEC}}=\right.$ $35.87 \times 10^{4}$; Table 1 , run 5).

Kinetics analysis. We further studied the reaction kinetics by using in situ FT-IR technique (Fig. 4). At fixed monomer and initiator concentrations $\left([\mathrm{Glu}-\mathrm{NCA}]_{0}=0.19 \mathrm{M}\right.$ and $[\mathrm{DMEA}]_{0}=$ $\left.4.0 \times 10^{-4} \mathrm{M}\right)$, the conversion of Glu-NCA with time was monitored by in situ FT-IR at various catalyst concentrations ([1,3Bis-HFAB $]_{0}=1.7,3.3,5.0,6.7$, and $17 \mathrm{~mol} \%$ vs. monomer) until full conversion was reached. Sampling was from $2800 \mathrm{~cm}^{-1}$ to $650 \mathrm{~cm}^{-1}$ at 8 wavenumber resolution and the automatic sampling interval was $10 \mathrm{~s}$, which guaranteed the real-time data acquisition of polymerization (Fig. $4 \mathrm{a}, \mathrm{b}$ ). The polymerization possesses classic two-stage propagation, which is consistent with the literature reports. The ROP of Glu-NCA in a number of solvents is shown to proceed at two successive rates following a relatively rapid initiation. The two-stage propagation is due to the transition of polypeptide chain from $\beta$ (non-helical, low DP) to $\alpha$ (helical, high DP) configuration during growth ${ }^{67,68}$. The rate constant for the second propagation step is at least several times larger than that for the first. Thus, the whole polymerization rate is largely dependent on the second stage propagation. As shown in Fig. 4, a first-order dependence of polymerization rate on monomer concentration was observed at the second propagation in each experiment. The corresponding apparent rate constants $\left(k_{\mathrm{app}}=1.50 \times 10^{-3} \mathrm{~s}^{-1}, 1.20 \times 10^{-3} \mathrm{~s}^{-1}, 9.98 \times\right.$ $10^{-4} \mathrm{~s}^{-1}, 9.29 \times 10^{-4} \mathrm{~s}^{-1}$, and $\left.6.29 \times 10^{-4} \mathrm{~s}^{-1}\right)$ were obtained from the semilogarithmic plots $\operatorname{Ln}\left([\mathrm{M}]_{0} /[\mathrm{M}]_{\mathrm{t}}\right)=k_{\text {app }}$ t. The plot of $\operatorname{Ln} k_{\text {app }}$ versus $\operatorname{Ln}[1,3-B i s-H F A B]_{0}$ is linear, and the gradient of the best-fit line is -0.3785 . Therefore, the kinetic order in catalyst is equal to -0.40 (within experimental errors). The minus order in catalyst indicates that high loading amount of catalyst in the system can cause a decrease of the polymerization rate.

The dependence of polymerization rate on initiator concentration was also determined (Fig. 4c, d). At fixed monomer and catalyst concentrations ([Glu-NCA $]_{0}=0.19 \mathrm{M}$ and $[1,3-\mathrm{Bis}-$ $\left.\mathrm{HFAB}]_{0}=1.58 \times 10^{-3} \mathrm{M}\right)$, the conversion of Glu-NCA with time was monitored at various initiator concentrations ([DMEA $]_{0} /$ $[1,3-\mathrm{Bis}-\mathrm{HFAB}]_{0}=1,0.5,0.25,0.125$, and 0.0625). Again, the consumption of the monomer follows the first-order kinetics. Hence the kinetic order in initiator is 1.45 (within experimental errors). As a result, the polymerization rate law is $R_{\mathrm{p}}=-\mathrm{d}[\mathrm{M}] / \mathrm{dt}=k_{\mathrm{p}}[1,3-\mathrm{Bis}-\mathrm{HFAB}]^{-0.40}[\mathrm{DMEA}]^{1.45}[\mathrm{NCA}]$.

NMR study of interactions between catalyst, monomer, and propagating chain. To understand the high activity and selectivity of polymerization at a molecular level, we investigated the interactions of 1,3-Bis-HFAB with Glu-NCA monomer, initiator, and propagating chains by using nuclear magnetic resonance (NMR) spectroscopy (Fig. 5). The ${ }^{1} \mathrm{H}$ NMR comparative study of 1,3-Bis-HFAB, Glu-NCA and 1,3-Bis-HFAB/Glu-NCA mixture revealed that 1,3-Bis-HFAB didn't induce the ROP of NCA and acted as a hydrogen-bonding donor to Glu-NCA. When 1,3-BisHFAB was mixed with equivalent Glu-NCA monomer in anhydrous DCM- $\mathrm{d}_{2}$ and monitored at room temperature for $24 \mathrm{~h}$, no evidence of polymer was observed in the ${ }^{1} \mathrm{H}$ NMR spectrum. Due to the hydrogen-bonding interaction between Glu-NCA and 1,3Bis-HFAB, the -OH of 1,3-Bis-HFAB shifted downfield from 3.66 to $3.92 \mathrm{ppm}$ in the ${ }^{1} \mathrm{H}$ NMR spectrum. Only one hydroxyl proton signal was observed, indicative of a fast equilibrium on the NMR time scale (Fig. 5a and Supplementary fig. 2). In addition, the $-\mathrm{CF}_{3}$ of 1,3-Bis-HFAB also showed a downfield chemical shift (from -75.92 to $-75.87 \mathrm{ppm}$ ) in the ${ }^{19} \mathrm{~F}$ NMR spectrum (Fig. $5 \mathrm{~b}$ and Supplementary fig. 3). The hydrogen-bonding interactions between 1,3-Bis-HFAB and the oxygen of carbonyl can dramatically enhance the activity of the carbonyl group. 
a

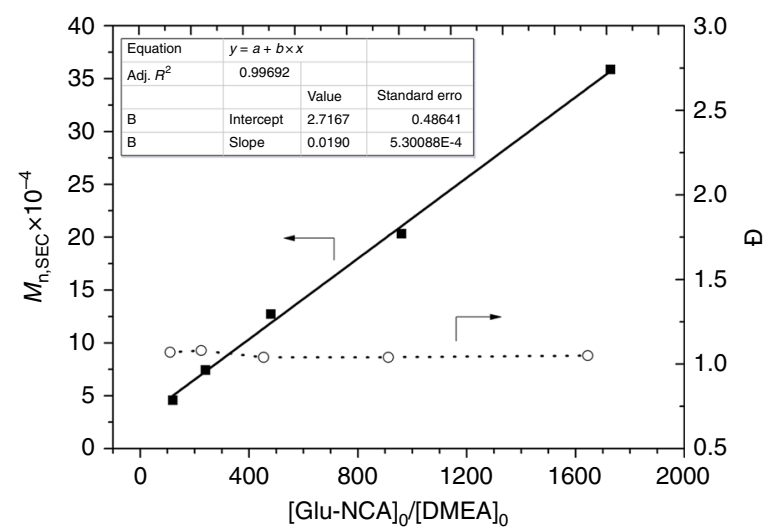

C

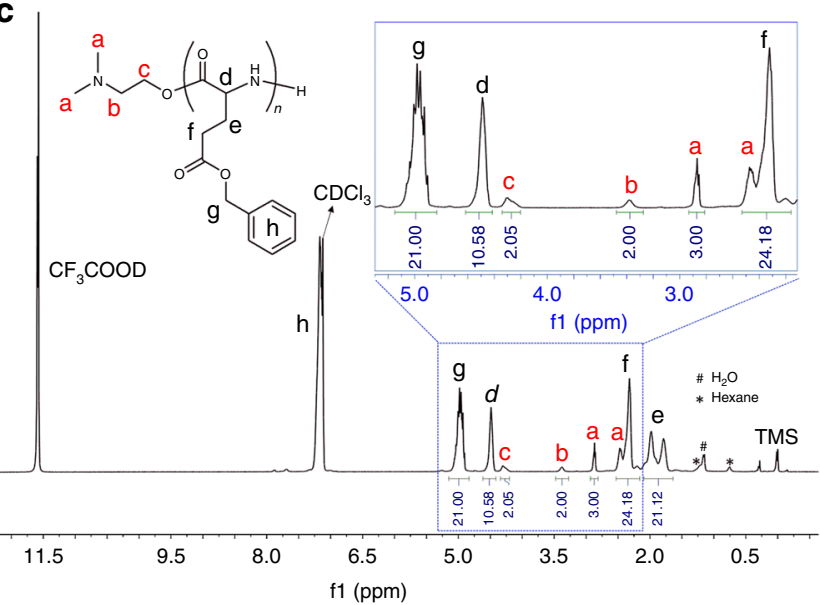

b

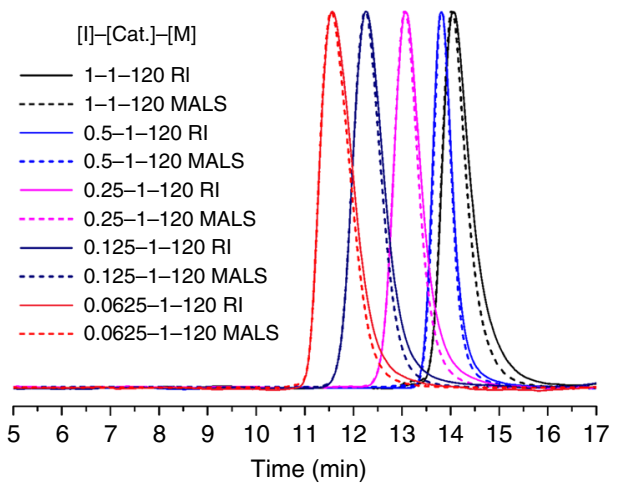

d

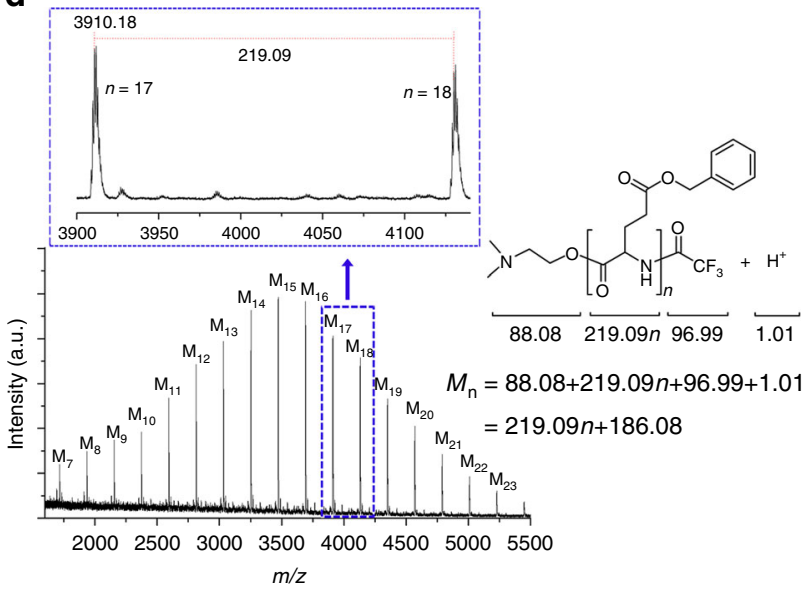

Fig. 3 Characterization of polypeptides synthesized from ROP of Glu-NCA initiated by DMEA in the presence of 1,3-Bis-HFAB catalyst. a plots of [Glu$\mathrm{NCA}]_{0} /[\mathrm{DMEA}]_{0}$ vs $\mathrm{M}_{\mathrm{n}, \mathrm{SEC}}$ and $[\mathrm{Glu}-\mathrm{NCA}]_{0} /[\mathrm{DMEA}]_{0}$ vs $\bigoplus_{;}$; b SEC traces of obtained polypeptides (Table 1, runs 1-5, solid and dash lines represents RI and MALS responses, respectively); ${ }^{1} \mathrm{H}$ NMR spectrum of $\mathrm{PBLG}_{10}\left(500 \mathrm{M}, 25^{\circ} \mathrm{C}, \mathrm{CDCl}_{3} / \mathrm{CF}_{3} \mathrm{COOD}=2\right.$, the $\mathrm{M}_{\mathrm{n} \text {, calcd }}$ is 2192 and the $\mathrm{M}_{\mathrm{n}, \mathrm{NMR}}$ calculated based on the integral ratio of $\mathrm{H}^{9} / \mathrm{H}^{b}$ is 2302 ; d MALDI-TOF MS spectrum of $\mathrm{PBLG}_{15}$ (the chain-end was capped with trifluoroacetyl group by using trifluoroacetic anhydride). (Source data are provided as a Source Data file)

The initiator, DMEA, contains a primary alcohol and a tertiary amine. According to previous literature, the tertiary amine can trigger uncontrolled NCA polymerization via an activated monomer mechanism, resulting in ill-defined polypeptide ${ }^{3,4,69}$. However, the end-group analysis of polypeptide by ${ }^{1} \mathrm{H}$ NMR and MALDI-TOF in the present study shows that the tertiary amine of DMEA is totally silent during polymerization (Fig. 3c, d). In order to figure out the reason, we protected the hydroxyl group of DMEA with tert-butyldimethylsilane (resulting in DMEA-TMS') and investigated the effect of 1,3 -Bis-HFAB on the tertiary amine of DMEA. In the ${ }^{1} \mathrm{H}$ NMR spectrum of 1,3 -Bis-HFAB with equivalent DMEA-TMS', the -OH of 1,3-Bis-HFAB shifted downfield from 3.66 to $6.89 \mathrm{ppm}$ and the signals of DMEATMS' $\left(\mathrm{H}^{\mathrm{e}}, \mathrm{H}^{\mathrm{g}}\right.$, and $\mathrm{H}^{\mathrm{f}}$ ) also shifted downfield slightly (Fig. 5a and Supplementary Figs. 4 and 5). In the ${ }^{19} \mathrm{~F}$ NMR spectrum, the fluorine resonance of $-\mathrm{CF}_{3}$ in 1,3-Bis-HFAB shifted downfield from -75.92 to $-75.61 \mathrm{ppm}$ (Fig. 5b and Supplementary fig. 3). The large change in chemical shift of the -OH of 1,3-Bis-HFAB $(\Delta=3.23)$ suggests that a strong hydrogen-bonding interaction takes place between 1,3-Bis-HFAB and the tertiary amine of DMEA. We further found that, DMEA-TMS', in the absence of 1,3-Bis-HFAB, could trigger the ROP of Glu-NCA via activated monomer mechanism. Kinetics studies via in situ FI-IR showed that the polymerization was very slow $(24 \mathrm{~h}, 92 \%$ monomer conversion) and a first-order dependence of polymerization rate on monomer concentration was not observed, indicating a slow initiation of the polymerization. The SEC demonstrated that the resultant polypeptide possessed an ultrahigh molecular weight $\left(\mathrm{M}_{\mathrm{n}, \mathrm{SEC}}=2.67 \times 10^{5}\right.$, ten times that of the calculated molecular weight $\left.M_{n, \text { calcd }}=2.63 \times 10^{4}\right)$ and a very broad molecular weight distribution $(Đ=1.63)$ (Supplementary fig. 6). However, in the presence of 1,3-Bis-HFAB, DMEA-TMS' cannot initiate the polymerization, which indicates that the strong hydrogenbonding interaction can neutralize the initiation capability of the tertiary amine to trigger polymerization. So, the primary alcohol is the only initiating site, which is consistent with the conclusion of end-group analysis by ${ }^{1} \mathrm{H}$ NMR and MALDI-TOF MS spectrum (Fig. 3c, d). If the tertiary amine in DMEA was involved in the initiation of polymerization, an activated monomer mechanism of NCA polymerization could be triggered and the initiator would not quantitatively remain at the polymer chain-ends after polymerization, which would give much higher experimental $M_{n}$ than the theoretical one. This is further solidified by studying the ROP of Glu-NCA initiated by $\mathrm{N}, \mathrm{N}$ dimethyl-1,2-ethanediamine (DMEDA, $\left(\mathrm{CH}_{3}\right)_{2} \mathrm{NCH}_{2} \mathrm{CH}_{2} \mathrm{NH}_{2}$ ) in the absence of 1,3-bis-HFAB (conditions: [Glu-NCA]/ $\left.[\mathrm{DMEDA}]=100,[\text { Glu-NCA }]_{0}=0.19 \mathrm{M}, 25^{\circ} \mathrm{C}\right)$. DMEDA has both tertiary amine and primary amine in its molecular structure and can trigger the NCA polymerization via both mechanisms. The SEC characterization demonstrated that the resultant polypeptide possessed a bimodal molecular weight distribution $(Đ=1.38)$ and the experimental molecular weight 


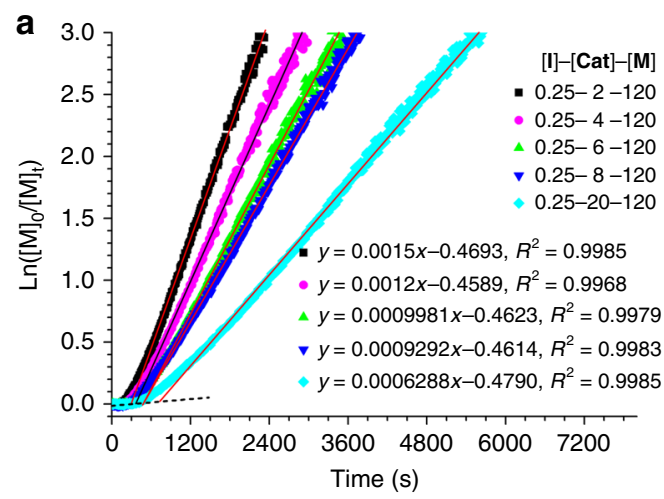

C

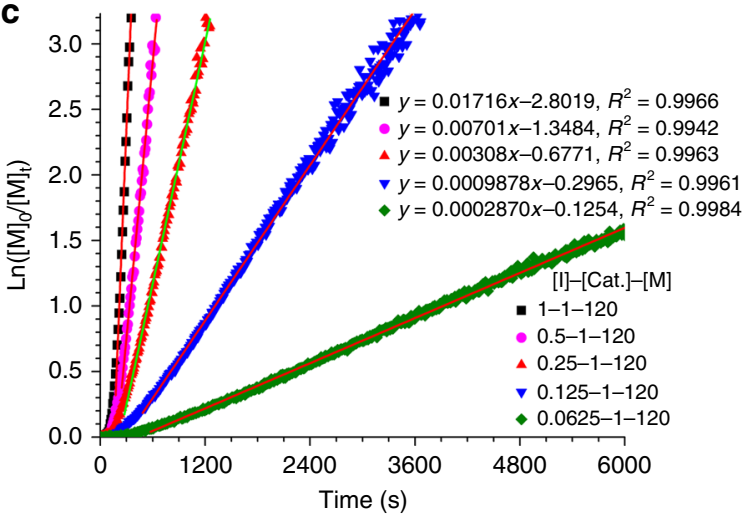

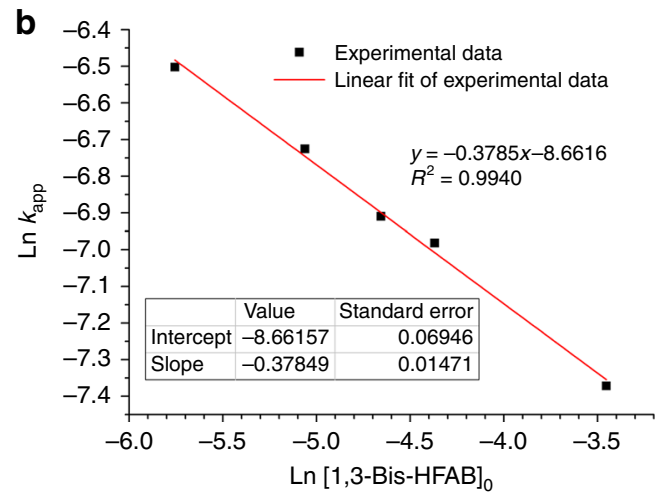

d

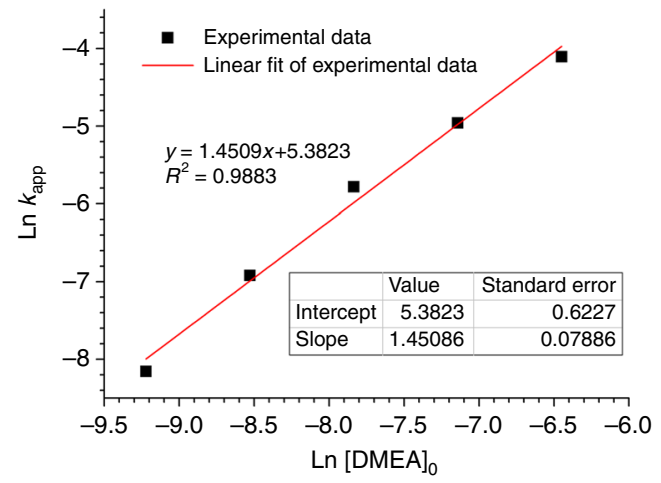

Fig. 4 Kinetics study of Glu-NCA polymerization catalyzed by 1,3-Bis-HFAB at room temperature in $\mathrm{CH}_{2} \mathrm{Cl}_{2}$. a, b $[1,3-\mathrm{Bis}-\mathrm{HFAB}]_{0}=1.7-17$ mol\% vs. $[\text { Glu-NCA }]_{0},[D M E A]_{0}=4 \times 10^{-4} \mathrm{M}$ and $[\text { Glu-NCA }]_{0}=0.19 \mathrm{M} ; \mathbf{c}, \mathbf{d}[1,3-\mathrm{Bis}-\mathrm{HFAB}]_{0}=1.58 \times 10^{-3} \mathrm{M},[\mathrm{DMEA}]_{0}=0.05-0.8 \mathrm{~mol} \% \mathrm{vs} .[\mathrm{Glu}-\mathrm{NCA}]_{0}$ and $[\mathrm{Glu}-\mathrm{NCA}]_{0}=0.19 \mathrm{M}$. (Source data are provided as a Source Data file)

$\left(\mathrm{M}_{\mathrm{n}, \mathrm{SEC}}=4.71 \times 10^{4}\right)$ is more than two times higher than the theoretical molecular weight $\left(\mathrm{M}_{\mathrm{n} \text {,calcd }}=2.19 \times 10^{4}\right)$ (Supplementary fig. 7).

Since the polymer chain-end will be primary amine group after initiating by the hydroxyl group of DMEA, we further investigated the interaction of 1,3-Bis-HFAB with polymer chainend by using 2-amino-2-phenylacetate (MAP), as a model molecule. The model molecule has a structure similar to the polymer chain end. The ${ }^{1} \mathrm{H}$ NMR results revealed that hydrogen bonding was also formed between 1,3-Bis-HFAB and chain-end primary amine group. In the presence of 1,3-Bis-HFAB, the signal of the primary amine group in MAP shifted downfield from 1.84 to $4.21 \mathrm{ppm}$ and the signal of the hydroxyl protons in 1,3-BisHFAB shifted downfield from 3.66 to 4.21 ppm (Fig. 5a and Supplementary fig. 8). In the ${ }^{19} \mathrm{~F}$ NMR spectrum, the fluorine resonance of $-\mathrm{CF}_{3}$ in 1,3-Bis-HFAB shifted downfield from -75.92 to $-75.68 \mathrm{ppm}$ (Fig. $5 \mathrm{~b}$ and Supplementary fig. 3). These results indicate that the nucleophilic character of the chainend primary amine group decreases upon formation of hydrogenbonding with 1,3-Bis-HFAB. By increasing of the loading amount of 1,3-Bis-HFAB in the system, the polymerization slowed down, which is consistent with the kinetic study results. However, under identical reaction conditions, polymerization experiments with different 1,3-Bis-HFAB loadings resulted in polymers with similar targeted $M_{n}$ and very low $Ð$ (Table 1 , runs 7-10). This suggests that 1,3-Bis-HFAB transforms the active species to dormant species without killing them and that a quick and reversible exchange exists between the free and dormant primary amine. This faster (vs. the propagation) and reversible exchange gives all amine groups an equal chance to trigger the polymerization. It seems that the catalyst is moving quickly between different chain-end primary amine groups. The dormant/active site exchange of primary amine group is further supported by the result from in situ FT-IR monitoring of polymerization (Fig. 6). The rate of polymerization slowed down after adding excess 1,3Bis-HFAB into the system during the polymerization, but the final polymer possessed $\mathrm{M}_{\mathrm{n}, \mathrm{SEC}}$ of $3.01 \times 10^{4}$ and very low $Ð$ of 1.05 (the SEC trace see Supplementary fig. 9). If the active species would be killed by 1,3-Bis-HFAB during polymerization, the polymerization would slow down and the $\mathrm{M}_{\mathrm{n}}$ of obtained polymer would be much higher than the targeted one $\left(2.63 \times 10^{4}\right)$.

According to previous reports in the literature, the chain-end primary amine is prone to side reactions during polymerization, which make it challenging to synthesize polymers with complex architectures like block copolymers ${ }^{3,4}$. Therefore, the hydrogen bonding formed between 1,3-Bis-HFAB and chain-end primary amine can provide a dynamical protection of the overactive chain-end amine and suppress the occurrence of side reactions in system. A control experiment was carried out by using a primary amine, n-hexylamine (HA) as initiator for the ROP of Glu-NCA, in the absence of 1,3-Bis-HFAB (conditions: [Glu-NCA]/[HA] = 120, $[\mathrm{Glu}-\mathrm{NCA}]_{0}=0.19 \mathrm{M}, 25^{\circ} \mathrm{C}, \mathrm{CH}_{2} \mathrm{Cl}_{2}$ ). The results showed that the polymerization was very slow, forming polypeptide with a broad molecular weight distribution $(4.5 \mathrm{~h}, 98 \%$ conv., $\left.\mathrm{M}_{\mathrm{n}, \mathrm{SEC}}=3.23 \times 10^{4}, \mathrm{D}=1.17, \mathrm{M}_{\mathrm{n}, \text { calcd }}=2.57 \times 10^{4}\right)$. A further kinetics study via in situ FT-IR method showed that the polymerization process did not have a constant reaction rate (Supplementary fig. 10). When the monomer conversion was above $82 \%$, the polymerization slowed down and deviated from the living polymerization due to side reactions. When the monomer/initiator ratio increased from 120 to 240, the results were even worse. Only $68 \%$ monomer were converted to polymer 

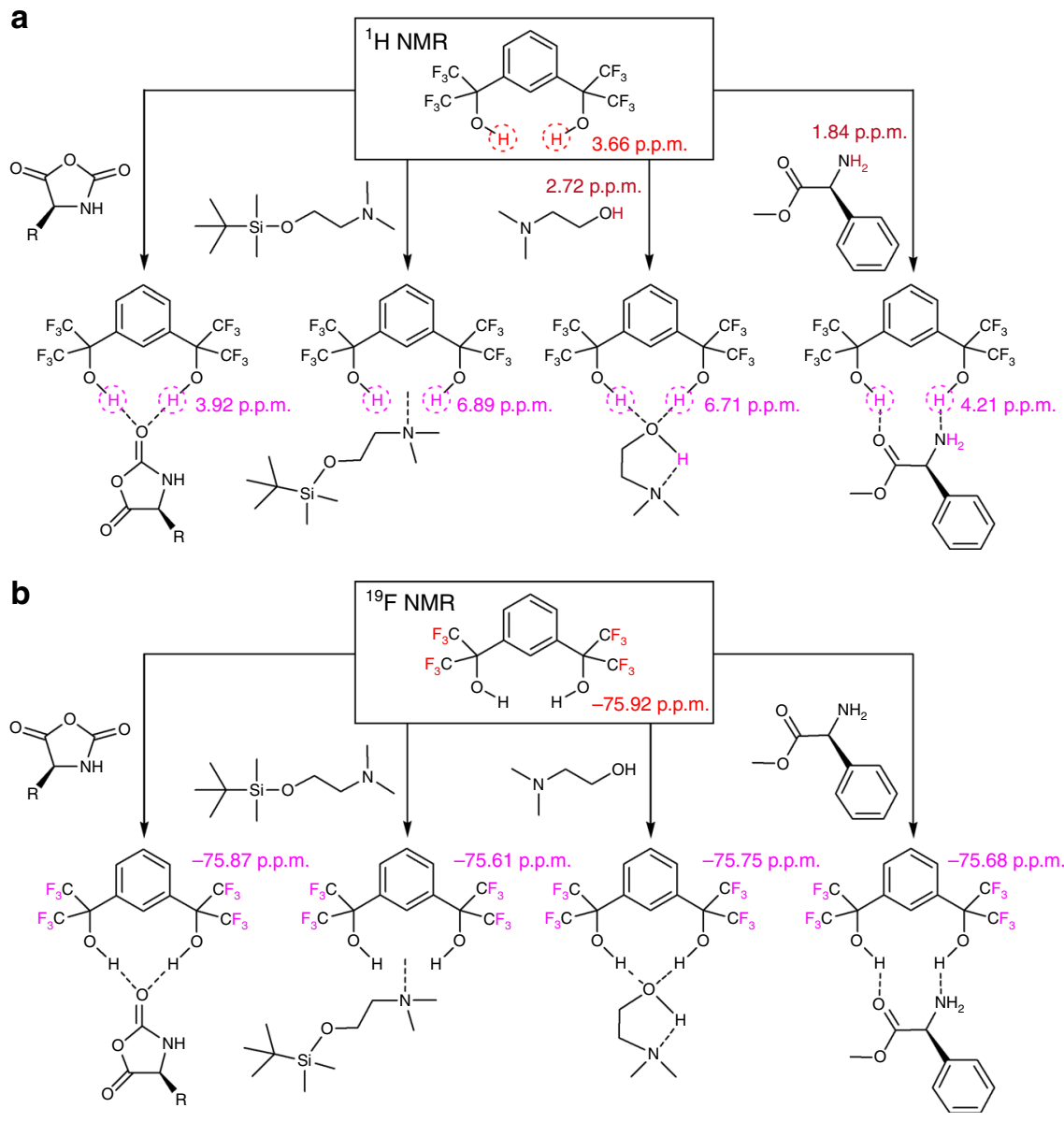

Fig. 5 Chemical shift changes of hydroxyl groups and fluorine atoms in 1,3-Bis-HFAB. a observed in the NMR spectra of 1,3-Bis-HFAB with Glu-NCA, DMEA-TMS', DMEA, and MAP, respectively; b observed in ${ }^{19} \mathrm{~F}$ NMR spectra (the comparative spectra see supplementary Figs. 2-5 and 8) (Source data are provided as a Source Data file)

a

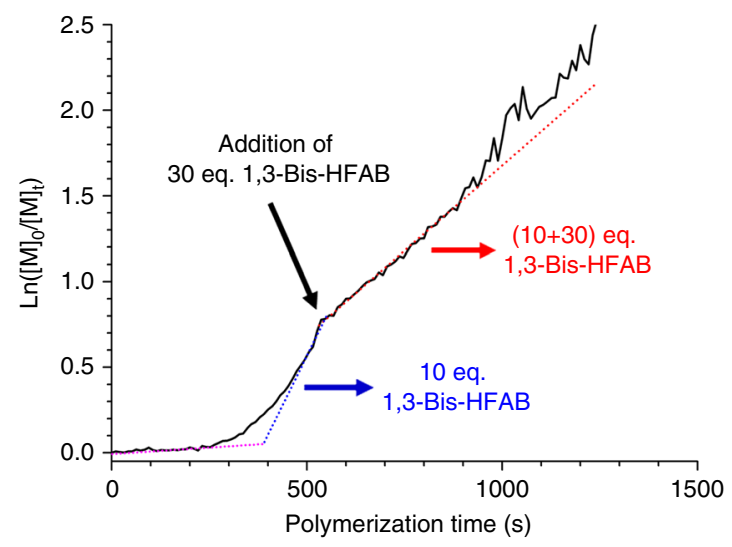

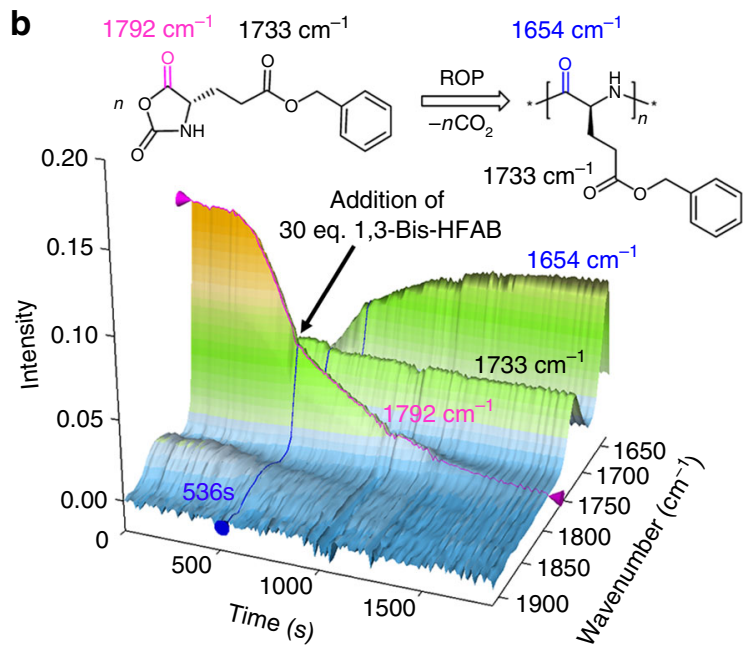

Fig. 6 In situ FT-IR monitoring of polymerization. a plot of $\operatorname{Ln}\left([\mathrm{M}]_{0} /\left([\mathrm{M}]_{t}\right)\right.$ vs. polymerization time (conditions: $[\mathrm{Glu}-\mathrm{NCA}]_{0}=0.19 \mathrm{M},[\mathrm{Glu}-\mathrm{NCA}]_{0} /[1,3-$ Bis-HFAB $\left.]_{0} /[D M E A]_{0}=120 /(10+30) / 1,25^{\circ} \mathrm{C}_{,} \mathrm{CH}_{2} \mathrm{Cl}_{2}\right)$; b corresponding 3D kinetic behavior profile from in situ FT-IR (Source data are provided as a Source Data file)

in $9 \mathrm{~h}$. The resultant polymer showed a bimodal SEC trace (with a shoulder peak $)$ and a higher molecular weight $\left(\mathrm{M}_{\mathrm{n}, \mathrm{SEC}-}=6.10 \times\right.$ $\left.10^{4}\right)$ than the theoretical molecular weight $\left(\mathrm{M}_{\mathrm{n} \text {,calcd }}=3.58 \times 10^{4}\right)$. Also, the monomer could not be completely converted to polypeptides even with a very long reaction time (1 day).
Computational study. To further understand the catalytic activity of 1,3-Bis-HFAB, we also carried out a computational study and investigated the interactions of 1,3-Bis-HFAB with Glu-NCA monomer, DMEA initiator, and propagating chain. The calculation was performed at the GGA/PBE/DNP level of 
theory. All of the constructed structures are fully optimized and electrostatic potential (ESP)-fitting charges are derived from the DFT calculation. The lowest-energy structure of 1,3-Bis-HFAB/ Glu-NCA complex $(\triangle \mathrm{E}=-57.61 \mathrm{kcal} / \mathrm{mol})$ demonstrated that the -OH of 1,3-Bis-HFAB formed hydrogen-bonding with the $\mathrm{C}$ $(5)=\mathrm{O}$ of NCA monomer. The charges assigned to the two hydrogen atoms of -OH groups in 1,3-Bis-HFAB decreased from $0.393 / 0.390$ to $0.380 / 0.238$ and the charge of the oxygen atom of NCA carbonyl group decreased from -0.350 to -0.389 (Supplementary fig. 11). The minimum energy structure of 1,3-BisHFAB/DMEA complex $(\triangle \mathrm{E}=-58.73 \mathrm{kcal} / \mathrm{mol})$ showed that the charge of the oxygen atom of DMEA increased from -0.497 to -0.229 after forming hydrogen-bonding with 1,3-Bis-HFAB, rendering the hydroxyl group of DMEA in a dormant state without nucleophilicity (Supplementary fig. 11). The complex structures of 1,3-Bis-HFAB/DMEA with one incorporated GluNCA monomer were also optimized $(\Delta \mathrm{E}=-80.63 \mathrm{kcal} / \mathrm{mol})$. When the first Glu-NCA monomer was ring-opened by DMEA, 1,3-Bis-HFAB would form hydrogen-bondings with the tertiary amine from DMEA and the primary amine derived from the ring-opened monomer. The charge of nitrogen atom of $-\mathrm{N}\left(\mathrm{CH}_{3}\right)_{2}$ increased from -0.126 to 0.318 and lost nucleophilicity. The charge of nitrogen atom of $-\mathrm{NH}_{2}$ increased from -0.867 to -0.713 , indicative of a decreased nucleophilicity of $-\mathrm{NH}_{2}$ (Supplementary fig. 11). When the secondary monomer is incorporated, the minimum energy structure $(\Delta \mathrm{E}=-59.93 \mathrm{kcal} / \mathrm{mol})$ showed that 1,3-Bis-HFAB was still bound to the tertiary amine of DMEA. The charge of nitrogen atom of tertiary amine is 0.197 and has no nucleophilicity. The above is consistent with the polymerization result that the tertiary amine is not capable of triggering the polymerization in the presence of 1,3-Bis-HFAB after opening the first cyclic NCA monomer molecule.

Proposed polymerization mechanism. On the basis of the results from polymerization kinetics, NMR experiments and computational calculation, a plausible reaction pathway is shown in Scheme 3. As shown, multiple hydrogen-bonding equilibriums involving NCA monomer, initiator (DMEA), catalyst (1,3-Bis$\mathrm{HFAB}$ ) and propagating polymer chain exist. We postulate that the catalysis proceeds by simultaneous activation of the carbonyl of a NCA monomer and dynamic protection of the polymer chain-end amine group via hydrogen bonding to 1,3-Bis-HFAB. Nucleophilic ring-opening of the NCA leads to propagation, whereby the ring-opened NCA forms the propagating amine for the subsequent addition of monomer (Fig. 7). During polymerization, 1,3-Bis-HFAB moves between monomer and polymer chain-ends and plays triple roles through donating hydrogenbonding: (1) increasing initiation and propagation rates by activating monomer; (2) dynamically protecting the overactive propagating primary amine from side reactions; and (3) totally silencing the tertiary amine of initiator after the initiation step. Although the high loading of 1,3-Bis-HFAB will increase the concentration of dormant species in the system and consequently cause a slight decrease of polymerization activity, this negative side effect can be partly compensated for by the activation of NCA monomer by 1,3-Bis-HFAB. That is why the polymerization can still proceed at a high rate.

NCA monomer extension and catalyst residue analysis. In order to explore the generality of this strategy for polypeptide synthesis, we also investigated the homopolymerizations of LysNCA and Alkynyl-NCA and the copolymerizations of Glu-NCA with Lys-NCA and Alkynyl-NCA (Table 1, runs 11-19). The polymerization results showed that the method is not monomer specific and can be used to prepare a series of well-defined random/block (co)polypeptides. The polymerization activity is different, depending on the monomer's structure, but all polymerization of these monomers can be completed in $10 \mathrm{~min}$ at room temperature with a monomer/initiator ratio of 120 . We also checked the 1,3-Bis-HFAB catalyst residue in the polymer samples by using ${ }^{1} \mathrm{H}$ NMR, ${ }^{19} \mathrm{~F}$ NMR, and EDS. We purposely prepared a high molecular weight polypeptide sample from polymerization with high loading of catalyst (conditions: [Glu$\mathrm{NCA}] /[\mathrm{DMEA}] /[1,3-\mathrm{Bis}-\mathrm{HFAB}]=120 / 0.25 / 10, \quad[$ Glu-NCA $]=$ $\left.0.19 \mathrm{M}, 25^{\circ} \mathrm{C}\right)$. When the polymerization is complete, and the resultant polypeptide was precipitated using methanol, a further two-step washing process of the precipitated polypeptide with methanol can totally remove the catalyst from the final polymer. The ${ }^{1} \mathrm{H}$ NMR, ${ }^{19} \mathrm{~F}$ NMR, and EDS spectra show no 1,3-Bis-HFAB catalyst residue in the final polypeptide (Supplementary figs. 1221). Furthermore, we also evaluated the cytotoxicity of the final polypeptide by doing in vitro cell experiments as followers. Briefly, human HepG2 cells were seeded in 96-well plates with a density of $5 \times 10^{3}$ cells per well and incubated overnight. Subsequently, the cells were incubated for $48 \mathrm{~h}$ with various concentrations of the extract of the final polypeptides (the preparation of extract of polypeptide follows international standard ISO 10993-12:2012). Afterwards, the cytotoxicity was evaluated by adding CCK- 8 solution to each well of the plate. The cell viabilities with the extracts of polypeptide exceeded 95\% (Supplementary fig. 22). Also, by using live/dead cell staining technique, stained live and dead cells can be visualized by fluorescence microscopy. From fluorescence microscopy images, we easily found that the cells viabilities with polypeptide extracts were comparable to the blank sample (Supplementary fig. 23). These results suggest that the final polypeptide does not show any cytotoxicity to HepG2 cells.

\section{Discussion}

In this study, we report a nonconventional catalysis methodology of fluorinated alcohol and successfully applied it to controlled synthesis of polypeptides. The methodology has some unique advantages over existing ones; free of cocatalyst, free of metal, free of high-boiling point solvent, high activity, and selectivity at room temperature. In addition, the 1,3-Bis-HFAB catalyst and the aminoalcohol initiator used in this study are all commercially available organic chemicals and the catalyst can be easily removed from final polypeptide after polymerization. These characteristics are crucial for the high-value-added applications of polypeptides in microelectronic and medical fields. Further development of this methodology will be targeted towards (1) expanding NCA monomers, (2) functionalizing polypeptides and polypeptide hybrid copolymers by designing new initiators.

\footnotetext{
Methods

Measurements. ${ }^{1} \mathrm{H},{ }^{19} \mathrm{~F}$, and ${ }^{13} \mathrm{C}$ NMR spectra were recorded on a Bruker AV500 spectrometer (FT, $500 \mathrm{MHz}$ for ${ }^{1} \mathrm{H}$ and ${ }^{19} \mathrm{~F} ; 125 \mathrm{MHz}$ for ${ }^{13} \mathrm{C}$ ). Chemical shifts are given in ppm and were referenced to the resonance for residual solvent ( $\delta 7.26$ for $\mathrm{CDCl}_{3}$ and 5.32 for $\mathrm{CD}_{2} \mathrm{Cl}_{2}$ ). Anhydrous $\mathrm{CD}_{2} \mathrm{Cl}_{2}(99.9$ atom \% D) was used for the NMR study of the hydrogen-bonding interactions between catalyst, monomer and propagating chain. A mixed deuterated solvent $\left(\mathrm{CDCl}_{3} / \mathrm{CF}_{3} \mathrm{COOD}=2\right)$ was used for the ${ }^{1} \mathrm{H}$ NMR characterization of polypeptide oligomer. Matrix-assisted laser desorption ionization time-of-flight (MALDI-TOF) mass spectra were collected on a Bruker UltraFLEX MALDI-TOF mass spectrometer in the reflector mode. 2,5Dihydroxybenzoic acid (DHB) was used as matrices, and dichloromethane(85\%)/ trifluoroacetic acid (15\%) was used as solvent. No cationic agent was added. Energy dispersive X-ray spectroscopy (EDS) analysis was carried out with a JSM-7500F scanning electron microscope (SEM, JEOL, Japan). The polymer film sample for EDS analysis was prepared by using solution spin coating method and was metalized with a sputtered gold layer before testing. The in situ FT-IR monitoring of NCA polymerization was carried out by using TENSOR II with MCT Detector from BRUKER. An attenuated total reflectance (ATR) diamond probe was connected to the reaction flask via AgX Fiber (Silver Halide, $9.5 \mathrm{~mm} \times 1.5 \mathrm{~m}$ ). Sam-
} pling is from $2800 \mathrm{~cm}^{-1}$ to $650 \mathrm{~cm}^{-1}$ at 8 wavenumber resolution and the 


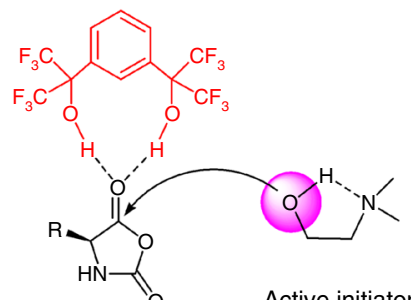

Active initiator
Fast and reversible exchange reaction $\stackrel{k_{\mathrm{ex} 1}\left(k_{\mathrm{ex} 1}>>k_{\mathrm{i}}>k_{\mathrm{p}}\right)}{\longrightarrow}$

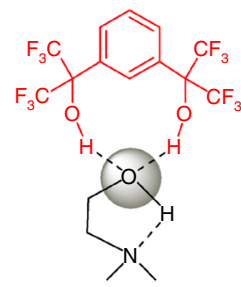

Dormant initiator

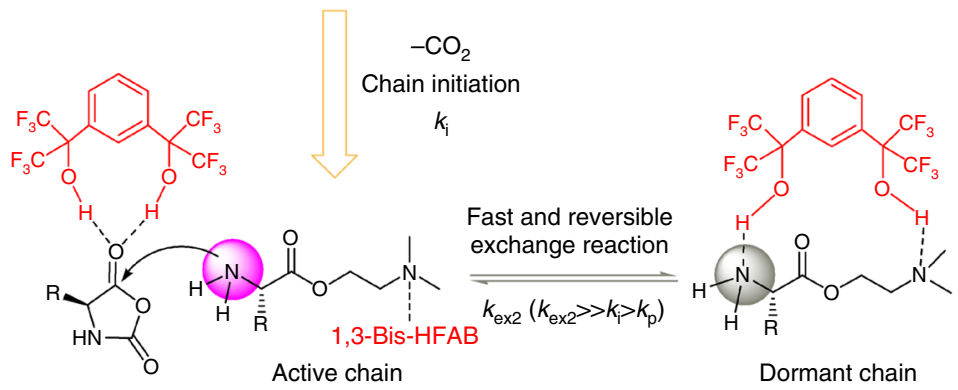

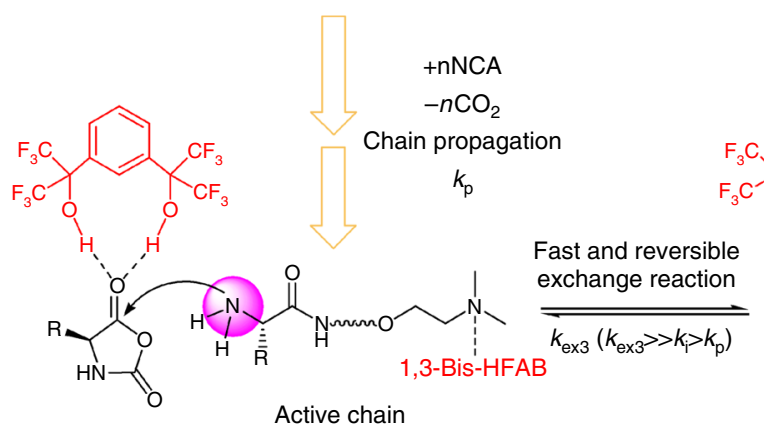<smiles>COC(=O)C(F)(F)c1cccc(C(F)(F)F)c1</smiles>

Dormant chain

Fig. 7 Proposed mechanism of ROP of Glu-NCA catalyzed by 1,3-Bis-HFAB. The nucleophilic ring-opening of the NCA by DMEA in the presence of 1,3-BisHFAB leads to the initiation of polymerization, whereby the ring-opened NCA releases one carbon dioxide molecule and forms the propagating amine for the subsequent addition of NCA monomers. During polymerization, multiple hydrogen-bonding equilibriums involving NCA monomer, initiator (DMEA), catalyst (1,3-Bis-HFAB), and propagating polymer chain exist. The catalysis proceeds by simultaneous activation of the carbonyl of NCA monomer and dynamic protection of the polymer chain-end amine group via hydrogen bonding to 1,3-Bis-HFAB

automatic sampling interval is $10 \mathrm{~s}$. The real-time concentration of NCA was quantified by measuring the intensity of NCA's anhydride peak at $1792 \mathrm{~cm}^{-1}$ Polymer characterizations were carried out by using Agilent 1260 infinity SEC instrument. The fractionation module was connected with three different detectors (from Wyatt Technology), Optilab T-rEX RI detector, ViscoStar-II viscometer and DAWN HELEOS-II multiangle laser-light scattering (MALLS) detector at a laser wavelength of $690 \mathrm{~nm}$. Three $7.8 \times 300 \mathrm{~mm}$ columns (Styragel ${ }^{\oplus}$ HT 2 DMF, Styragel $^{\oplus}$ HT 3 DMF and Styragel ${ }^{\oplus}$ HT 4 DMF) and one guard column were used for polymer fractionation. The columns were calibrated with a series of polystyrene standards (Polymer Standard Service, U.S.A.). HPLC-grade DMF (containing $0.1 \mathrm{M} \mathrm{LiBr}$ ) was used as the mobile phase at a flow rate of $1.0 \mathrm{~mL} / \mathrm{min}$. The whole SEC system was equilibrated in mobile phase at $60^{\circ} \mathrm{C}$. Polymer solutions with concentrations between 5.0 and $10.0 \mathrm{mg} \mathrm{mL}^{-1}$ were injected with an injection volume of $200 \mu \mathrm{L}$. ASTRA software from Wyatt Technology was used for the data collection and analysis. The absolute molecular weights of resultant polypeptides were calculated with $\mathrm{dn} / \mathrm{dc}$ values $\left(\mathrm{dn} / \mathrm{dc}(\mathrm{PBLG})=0.104 \mathrm{~mL} \mathrm{~g}^{-1}, \mathrm{dn} / \mathrm{dc}(\mathrm{PZLL})=\right.$ $0.123 \mathrm{~mL} \mathrm{~g}^{-1}, \mathrm{dn} / \mathrm{dc}(\mathrm{PABLG})=0.126 \mathrm{~mL} \mathrm{~g}^{-1}, \mathrm{dn} / \mathrm{dc}(\mathrm{PBLG}-\mathrm{co}-\mathrm{PZLL})=$ $0.114 \mathrm{~mL} \mathrm{~g}^{-1}, \mathrm{dn} / \mathrm{dc}($ PBLG-co-PABLG $)=0.115 \mathrm{~mL} \mathrm{~g}^{-1}$. PBLG, PZLL, and PABLG represent polypeptides obtained from ROP of Glu-NCA, Lys-NCA and AlkynylNCA, respectively.) The Density Functional Theory (DFT) calculation was performed at the GGA/PBE/DNP level of theory. All of the constructed structures are fully optimized and electrostatic potential (ESP)-fitting charges are derived from the DFT calculation.

Polymerization procedure. A typical procedure for the ring-opening polymerization of NCA was performed at $25^{\circ} \mathrm{C}$ in a Braun Labmaster glovebox. Before polymerization, an attenuated total reflectance (ATR) diamond probe was connected to the reaction flask via a AgX Fiber (Silver Halide, $9.5 \mathrm{~mm} \times 1.5 \mathrm{~m}$ ). A solution of the initiator (DMEA) and catalyst (1,3-Bis-HFAB) in $4 \mathrm{~mL}$ of reaction solvent (DCM) was firstly added into the flask. After stirring at $25^{\circ} \mathrm{C}$ for $1 \mathrm{~min}$, the monomer solution of $0.4 \mathrm{~g}$ Glu-NCA monomer in $4 \mathrm{~mL}$ DCM was then quickly added into the flask to start the polymerization and the auto sampling system was switched on immediately. Sampling is from $2800 \mathrm{~cm}^{-1}$ to $650 \mathrm{~cm}^{-1}$ at 8 wavenumber resolution and the automatic sampling interval is $10 \mathrm{~s}$. When full conversion was achieved from the in situ FT-IR spectra, $0.2 \mathrm{~mL}$ of the reaction mixture was taken out from the reaction system and diluted to $10 \mathrm{mg} / \mathrm{mL}$ by using HPLC-grade DMF (containing 0.1 M LiBr). The solution was then used for SEC characterization to determine the molecular weight and molecular weight distribution of the obtained polypeptides. The remaining reaction mixture was poured into methanol, sonicated, and centrifuged to remove the solvent. The white precipitate was collected and further washed twice with methanol and then dried overnight under vacuum to give the final polymer. Polypeptide with variable molecular weights was prepared by tuning the relative ratios of monomer to initiator [NCA]/[DMEA]. Homopolymerization of Lys-NCA or Alkynyl-NCA was operated by following above operations at $25^{\circ} \mathrm{C}$ with $[\mathrm{NCA}]_{0}=0.19 \mathrm{M}$. As for random copolymerizations of Glu-NCA with Lys-NCA or Alkynyl-NCA, the overall monomer concentration [Glu-NCA + Lys-NCA $]_{0}$ or [Glu-NCA + Alkynyl$\mathrm{NCA}]_{0}$ was fixed at $0.19 \mathrm{M}$. As for the sequential polymerization of Glu-NCA with Lys-NCA or Alkynyl-NCA, the polymerization of Glu-NCA was carried out firstly. When a full conversion of the Glu-NCA was achieved, the Lys-NCA or AlkynylNCA monomer was quickly added into reaction system. The whole polymerization process was monitored by in situ FT-IR in order to determine the adding time of the second kind of monomer.

Cell experiments. The human liver cancer cell line HepG2 was purchased from ATCC (American Type Culture Collection, VA). Before experiments, the cell was kept at $37^{\circ} \mathrm{C}$ in a humidified atmosphere of $5 \% \mathrm{CO}_{2}$ in dulbecco's modified eagle medium (with $10 \%$ fetal bovine serum, $25 \mathrm{mmol} \mathrm{L}^{-1}$ hydroxyethyl piperazine ethanesulfonic acid buffer, $100 \mathrm{U} \mathrm{mL}^{-1}$ penicillin, and $100 \mu \mathrm{g} \mathrm{mL}^{-1}$ streptomycin). The extract of the polypeptide sample was prepared by following international standard ISO 10993-12:2012. The cellular toxicity of the polypeptide samples was evaluated as follows. HepG2 cells were firstly seeded in 96-well plates with a density of $5 \times 10^{3}$ cells per well and incubated overnight. Subsequently, the cells were incubated for $48 \mathrm{~h}$ with various concentrations of the extract of polypeptides. Afterwards, the cytotoxicity was evaluated by adding Cell Counting Kit-8 (CCK-8) solution (from RayBiotech, Inc.) to each well of the plate. After incubation for $1 \mathrm{~h}$, 
the absorbance was investigated at $450 \mathrm{~nm}$ using a Multiskan MK3 Microplate Reader. For fluorescence microscopy, a live-dead cell staining kit from RayBiotech, Inc. was used. The live-dead cell staining kit provides the ready-to-use reagents for convenient discrimination between live and dead cells. The kit utilizes Live-Dye ${ }^{\mathrm{TM}}$, a cell-permeable green fluorescent dye $(\mathrm{Ex} / \mathrm{Em}=488 / 518 \mathrm{~nm})$, to stain live cells. Dead cells can be easily stained by propidium iodide (PI), a cell non-permeable red fluorescent dye $(\mathrm{Ex} / \mathrm{Em}=488 / 615)$. Stained live and dead cells can be visualized by fluorescence microscopy using a band-pass filter.

\section{Data availability}

The source data for Figs. 3-6 and Supplementary Figs, 2-10, 12-22 and 24-26 are provided with this paper. These source data were also deposited in the Figshare (https:// doi.org/10.6084/m9.figshare.8855750).

Received: 2 March 2019 Accepted: 17 July 2019

Published online: 09 August 2019

\section{References}

1. Deng, C. et al. Functional polypeptide and hybrid materials: precisionsynthesis via $\alpha$-amino acid $\mathrm{N}$-carboxyanhydride polymerization and emerging biomedical applications. Prog. Polym. Sci. 39, 330-364 (2014).

2. Lu, H. et al. Recent advances in amino acid $\mathrm{N}$-carboxyanhydrides and synthetic polypeptides: chemistry, self-assembly and biological applications. Chem. Commun. 50, 139-155 (2014).

3. Hadjichristidis, N., Iatrou, H., Pitsikalis, M. \& Sakellariou, G. Synthesis of well-defined polypeptide-based materials via the ring-opening polymerization of $\alpha$-amino acid N-carboxyanhydrides. Chem. Rev. 109, 5528-5578 (2009).

4. Deming, T. J. Polypeptide and polypeptide hybrid copolymer synthesis via NCA polymerization. Adv. Polym. Sci. 202, 1-18 (2006).

5. Deming, T. J. Transition metal-amine initiators for preparation of well-defined poly(gamma-benzyl L-glutamate). J. Am. Chem. Soc. 119, 2759-2760 (1997).

6. Deming, T. J. Facile synthesis of block copolypeptides of defined architecture. Nature 390, 386-389 (1997).

7. Peng, Y. L., Lai, S. L. \& Lin, C. C. Preparation of polypeptide via living polymerization of Z-Lys-NCA initiated by platinum complexes. Macromolecules 41, 3455-3459 (2008).

8. Dimitrov, I. \& Schlaad, H. Synthesis of nearly monodisperse polystyrenepolypeptide block copolymers via polymerisation of $\mathrm{N}$ carboxyanhydrides. Chem. Commun. 23, 2944-2945 (2003).

9. Lu, H. \& Cheng, J. Hexamethyldisilazane-mediated controlled polymerization of alpha-amino acid N-carboxyanhydrides. J. Am. Chem. Soc. 129, 14114-14115 (2007).

10. Peng, H., Ling, J. \& Shen, Z. Q. Ring opening polymerization of $\alpha$-amino acid $\mathrm{N}$-carboxyanhydrides catalyzed by rare earth catalysts: polymerization characteristics and mechanism. Polym. Chem. 50, 1076-1085 (2012).

11. Zhang, H., Nie, Y., Zhi, X., Du, H. \& Yang, J. Controlled ring-opening polymerization of alpha-amino acid $\mathrm{N}$-carboxy-anhydride by frustrated amine/borane lewis pairs. Chem. Commun. 53, 5155-5158 (2017).

12. $\mathrm{Wu}, \mathrm{Y}$., et al. Lithium hexamethyldisilazide initiated superfast ring opening polymerization of alpha-amino acid N-carboxyanhydrides. Nat. Commun., https://doi.org/10.1038/s41467-018-07711-y (2018).

13. Aliferis, T., Iatrou, H. \& Hadjichristidis, N. Living polypeptides. Biomacromolecules 5, 1653-1656 (2004).

14. Pickel, D. L., Politakos, N., Avgeropoulos, A. \& Messman, J. M. A mechanistic study of alpha-(amino acid)-N-carboxyanhydride polymerization: comparing initiation and termination events in high-vacuum and traditional polymerization techniques. Macromolecules 42, 7781-7788 (2009).

15. Vayaboury, W., Giani, O., Cottet, H., Deratani, A. \& Schue, F. Living polymerization of alpha-amino acid N-carboxyanhydrides (NCA) upon decreasing the reaction temperature. Macromol. Rapid Commun. 25, 1221-1224 (2004).

16. Habraken, G. J. M., Wilsens, K. H. R. M., Koning, C. E. \& Heise, A. Optimization of N-carboxyanhydride (NCA) polymerization by variation of reaction temperature and pressure. Polym. Chem. 2, 1322-1330 (2011).

17. Habraken, G. J. M., Peeters, M., Dietz, C. H. J. T., Koning, C. E. \& Heise, A. How controlled and versatile is N-carboxy anhydride (NCA) polymerization at $0{ }^{\circ} \mathrm{C}$ ? Effect of temperature on homo-, block- and graft (co)polymerization. Polym. Chem. 1, 514-524 (2010).

18. Zou, J. et al. A facile glovebox-free strategy to significantly accelerate the syntheses of well-defined polypeptides by $\mathrm{N}$-carboxyanhydride (NCA) ring opening polymerizations. Macromolecules 46, 4223-4226 (2013).

19. Huggins, M. L. Hydrogen bridges in organic compounds. J. Org. Chem. 1, 407-456 (1936).
20. Pauling, L. The shared-electron chemical bond. Proc. Natl Acad. Sci. USA 14, 359-362 (1928).

21. Latimer, W. M. \& Rodebush, W. H. Polarity and ionization from the standpoint of the Lewis theory of valence. J. Am. Chem. Soc. 42, 1419-1433 (1920).

22. Doyle, A. G. \& Jacobsen, E. N. Small-molecule H-bond donors in asymmetric catalysis. Chem. Rev. 107, 5713-5743 (2007).

23. Giacalone, F., Gruttadauria, M., Agrigento, P. \& Noto, R. Low-loading asymmetric organocatalysis. Chem. Soc. Rev. 41, 2406-2447 (2012).

24. Wende, R. C. \& Schreiner, P. R. Evolution of asymmetric organocatalysis: multi-and retrocatalysis. Green. Chem. 14, 1821-1849 (2012).

25. Phipps, R. J., Hamilton, G. L. \& Toste, F. D. The progression of chiral anions from concepts to applications in asymmetric catalysis. Nat. Chem. 4, 603 (2012).

26. $\mathrm{Yu}, \mathrm{S} . \& \mathrm{Pu}, \mathrm{L}$. Recent progress on using BINOLs in enantioselective molecular recognition. Tetrahedron 5, 745-772 (2015).

27. Brunel, J. M. BINOL: a versatile chiral reagent. Chem. Rev. 105, 857-898 (2005).

28. Chen, Y., Yekta, S. \& Yudin, A. K. Modified BINOL ligands in asymmetric catalysis. Chem. Rev. 103, 3155-3212 (2003).

29. Tran, N. T., Wilson, S. O. \& Franz, A. K. Cooperative hydrogen-bonding effects in silanediol catalysis. Org. Lett. 14, 186-189 (2011).

30. Schafer, A. G., Wieting, J. M., Fisher, T. J. \& Mattson, A. E. Chiral silanediols in anion-binding catalysis. Angew. Chem. Int. Ed. 125, 11531-11534 (2013).

31. Wurm, F. R. \& Klok, H. A. Be squared: expanding the horizon of squaric acidmediated conjugations. Chem. Soc. Rev. 42, 8220-8236 (2013).

32. Alemán, J., Parra, A., Jiang, H. \& Jørgensen, K. A. Squaramides: bridging from molecular recognition to bifunctional organocatalysis. Chem.-A Eur. J. 17, 6890-6899 (2011).

33. Yoon, T. P. \& Jacobsen, E. N. Privileged chiral catalysts. Science 299, 1691-1693 (2003).

34. Connon, S. J. Organocatalysis mediated by (thio)urea derivatives. Chem. A Eur. J. 12, 5418-5427 (2006).

35. Dong, S., Feng, X. \& Liu, X. Chiral guanidines and their derivatives in asymmetric synthesis. Chem. Soc. Rev. 47, 8525-8540 (2018).

36. Birman, V. B. Amidine-based catalysts (ABCs): design, development, and applications. Aldrichimica Acta 49, 23-33 (2016).

37. Zhang, X., Fevre, M., Jones, G. O. \& Waymouth, R. M. Catalysis as an enabling science for sustainable polymers. Chem. Rev. 118, 839-885 (2017).

38. Zhang, X., Jones, G. O., Hedrick, J. L. \& Waymouth, R. M. Fast and selective ring-opening polymerizations by alkoxides and thioureas. Nat. Chem. 8, 1047 (2016).

39. Thomas, C. \& Bibal, B. Hydrogen-bonding organocatalysts for ring-opening polymerization. Green. Chem. 16, 1687-1699 (2014).

40. Mespouille, L., Coulembier, O., Kawalec, M., Dove, A. P. \& Dubois, P. Implementation of metal-free ring-opening polymerization in the preparation of aliphatic polycarbonate materials. Prog. Polym. Sci. 39, 1144-1164 (2014).

41. Hillmyer, M. A. \& Tolman, W. B. Aliphatic polyester block polymers: renewable, degradable, and sustainable. Acc Chem. Res. 47, 2390-2396 (2014).

42. Kiesewetter, M. K., Shin, E. J., Hedrick, J. L. \& Waymouth, R. M. Organocatalysis: opportunities and challenges for polymer synthesis. Macromolecules 43, 2093-2107 (2010).

43. Colomer, I., Chamberlain, A. E. R., Haughey, M. B. \& Donohoe, T. J. Hexafluoroisopropanol as a highly versatile solvent. Nature Reviews. Chemistry 1, 0088 (2017).

44. Smart, B. E. \& Tatlow, J. C. (eds.). Organofluorine chemistry: principles and commercial applications (Plenum Press, New York, 1994).

45. Othon, C. M., Kwon, O. H., Lin, M. M. \& Zewail, A. H. Solvation in protein (un) folding of melittin tetramer-monomer transition. Proc. Natl Acad. Sci. USA 106, 12593-12598 (2009). (a).

46. Roccatano, D., Fioroni, M., Zacharias, M. \& Colombo, G. Effect of hexafluoroisopropanol alcohol on the structure of melittin: A molecular dynamics simulation study. Protein Sci. 14, 2582-2589 (2005).

47. Andersen, N. H. et al. Effect of hexafluoroisopropanol on the thermodynamics of peptide secondary structure formation. J. Am. Chem. Soc. 121, 9879-9880 (1999).

48. Khaksar, S. Fluorinated alcohols: a magic medium for the synthesis of heterocyclic compounds. J. Fluor. Chem. 172, 51-61 (2015).

49. Shuklov, I. A., Dubrovina, N. V. \& Boerner, A. Fluorinated alcohols as solvents, cosolvents and additives in homogeneous catalysis. Synthesis 2007, 2925-2943 (2007)

50. Begue, J. P., Bonnet-Delpon, D. \& Crousse, B. Fluorinated alcohols: a new medium for selective and clean reaction. Synlett 2004, 0018-0029 (2004).

51. Berkessel, A. \& Adrio, J. A. Dramatic acceleration of olefin epoxidation in fluorinated alcohols: activation of hydrogen peroxide by multiple H-bond networks. J. Am. Chem. Soc. 128, 13412-13420 (2016) 
52. De Visser, S. P., Kaneti, J., Neumann, R. \& Shaik, S. Fluorinated alcohols enable olefin epoxidation by $\mathrm{H} 2 \mathrm{O} 2$ : template catalysis. J. Org. Chem. 68, 2903-2912 (2003).

53. Berkessel, A., Andreae, M. R., Schmickler, H. \& Lex, J. Baeyer-Villiger oxidations with hydrogen peroxide in fluorinated alcohols: lactone formation by a nonclassical mechanism. Angew. Chem. Int. Ed. 41, 4481-4484 (2002).

54. De, K., Legros, J., Crousse, B. \& Bonnet-Delpon, D. Solvent-promoted andcontrolled aza-Michael reaction with aromatic amines. J. Org. Chem. 74, 6260-6265 (2009).

55. Choy, J., Jaime-Figueroa, S. \& Lara-Jaime, T. A novel practical cleavage of tertbutyl esters and carbonates using fluorinated alcohols. Tetrahedron Lett. 51, 2244-2246 (2010).

56. Heydari, A., Khaksar, S. \& Tajbakhsh, M. 1, 1, 1, 3, 3, 3Hexafluoroisopropanol: a recyclable organocatalyst for N-Boc protection of amines. Synthesis 2008, 3126-3130 (2008).

57. Azzouzi-Zriba, K., Bonnet-Delpon, D. \& Crousse, B. Transition metalcatalyzed cyclopropanation of alkenes in fluorinated alcohols. J. Fluor. Chem. 132, 811-814 (2011).

58. Khaksar, S., Heydari, A., Tajbakhsh, M. \& Bijanzadeh, H. R. A facile and efficient synthesis of $\beta$-amino alcohols using 2, 2, 2-trifluoroethanol as a metal-free and reusable medium. J. Fluor. Chem. 131, 106-110 (2010).

59. Kesavan, V., Bonnet-Delpon, D. \& Bégué, J. P. Fluoro alcohol as reaction medium: one-pot synthesis of $\beta$-hydroxy sulfoxides from epoxides. Tetrahedron Lett. 41, 2895-2898 (2000).

60. Matyjaszewski, K. \& Tsarevsky, N. V. Macromolecular engineering by atom transfer radical polymerization. J. Am. Chem. Soc. 136, 6513-6533 (2014).

61. Satoh, K. \& Kamigaito, M. Stereospecific living radical polymerization: dual control of chain length and tacticity for precision polymer synthesis. Chem. Rev. 109, 5120-5156 (2009).

62. Koumura, K., Satoh, K., Kamigaito, M. \& Okamoto, Y. Iodine transfer radical polymerization of vinyl acetate in fluoroalcohols for simultaneous control of molecular weight, stereospecificity, and regiospecificity. Macromolecules 39, 4054-4061 (2006).

63. Miura, Y. et al. Atom transfer radical polymerization of methyl methacrylate in fluoroalcohol: simultaneous control of molecular weight and tacticity. Macromolecules 38, 1041-1043 (2005).

64. Isobe, Y., Yamada, K., Nakano, T. \& Okamoto, Y. Stereocontrol in the freeradical polymerization of methacrylates with fluoroalcohols. J. Polym. Sci. Part A Polym. Chem. 38, 4693-4703 (2000).

65. Isobe, Y., Yamada, K., Nakano, T. \& Okamoto, Y. Stereospecific free-radical polymerization of methacrylates using fluoroalcohols as solvents. Macromolecules 32, 5979-5981 (1999).

66. Coulembier, O. et al. Hydrogen-bonding catalysts based on fluorinated alcohol derivatives for living polymerization. Angew. Chem. Int. Ed. 48, 5170-5173 (2009).

67. Lundberg, R. D. \& Doty, P. Polypeptides. XVII. A study of the kinetics of the primary amine-initiated polymerization of $\mathrm{N}$-carboxy-anhydrides with special reference to configurational and stereochemical effects. J. Am. Chem. Soc. 79, 3961-3972 (1957).

68. Idelson, M. \& Blout, E. R. Polypeptides. XV.1 infrared spectroscopy and the kinetics of the synthesis of polypeptides: primary amine initiated reactions. $J$. Am. Chem. Soc. 79, 3948-3955 (1957).
69. Kricheldorf, H. R. Polypeptides and 100 years of chemistry of $\alpha$-amino acid Ncarboxyanhydrides. Angew. Chem. Int. Ed. 45, 5752-5784 (2006).

\section{Acknowledgements}

This work is supported by grants from the National Natural Science Foundation of China (No. 21774071) and Natural Science Foundation of Shaanxi University of Science and Technology (No. 2017QNBJ-07). W.Z. thanks the support from the Youth HundredTalent Program of Shaanxi Province (No.SXBR9227), the National High-Level Foreign Expert Project (No.GDT20186100425), Biomass Chemistry and Materials Academician Workstation Project in SUST (No.134090002) and Northwest Polytechnic University High Performance Computing and Development Center. N.H. acknowledges the support of King Abdullah University of Science and Technology.

\section{Author contributions}

W.Z., Y.N., and N.H. conceived the idea, designed the experiments, evaluated the data and wrote the manuscript together. Y.L. and Z.F performed majority of the experiments and summarized results. J.L. carried out the computational studies. All of the authors reviewed, approved, and contributed to the final version of the manuscript.

\section{Additional information}

Supplementary Information accompanies this paper at https://doi.org/10.1038/s41467019-11524-y.

Competing interests: The authors declare no competing interests.

Reprints and permission information is available online at http://npg.nature.com/ reprintsandpermissions/

Peer review information: Nature Communications thanks the anonymous reviewer(s) for their contribution to the peer review of this work. Peer reviewer reports are available.

Publisher's note: Springer Nature remains neutral with regard to jurisdictional claims in published maps and institutional affiliations.

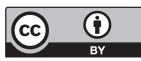

Open Access This article is licensed under a Creative Commons Attribution 4.0 International License, which permits use, sharing, adaptation, distribution and reproduction in any medium or format, as long as you give appropriate credit to the original author(s) and the source, provide a link to the Creative Commons license, and indicate if changes were made. The images or other third party material in this article are included in the article's Creative Commons license, unless indicated otherwise in a credit line to the material. If material is not included in the article's Creative Commons license and your intended use is not permitted by statutory regulation or exceeds the permitted use, you will need to obtain permission directly from the copyright holder. To view a copy of this license, visit http://creativecommons.org/ licenses/by/4.0/.

(C) The Author(s) 2019 